\title{
O ITALiano Na EScola PÚBLICa: conflitos históricos em Santa Catarina
}

\author{
Carolina Pizzolo Torquato*
}

RESUMO: Este artigo trata da diversidade linguística brasileira e, mais especificamente, do ensino do italiano nas escolas públicas de alguns municípios de Santa Catarina. Nas últimas décadas, algumas comunidades catarinenses, fundadas a partir da imigração italiana do final do século XIX, promulgaram leis municipais que incluíram o italiano em sua rede de ensino, embora os imigrantes italianos fossem, em sua grande maioria, exclusivamente dialetófonos. Além de abordar o repertório linguístico dos imigrantes, o artigo trata da repressão linguística sofrida por eles durante o Estado Novo, bem como das consequências dessa repressão para as novas gerações de descendentes. O objetivo do artigo é problematizar a relação que se estabelece entre a repressão linguística e os preconceitos ainda existentes quanto ao(s) dialeto(s), questionando o lugar do ensino do italiano nessas comunidades.

PALAVRAS-CHAVE: línguas de imigração; dialeto; italiano; talian; ensino.

ABSTRACT: Il presente articolo affronta il tema della diversità linguística brasiliana e, più specificamente, dell'insegnamento dell'italiano nelle scuole pubbliche di alcuni comuni dello Stato di Santa Catarina. Negl ultimi decenni, alcune comunità dello Stato, fondate a partire dall'immigrazione italiana della fine del XIX secolo, hanno promulgato leggi municipali che hanno incluso l'italiano nelle loro scuole, sebbene gli immigrati italiani fossero, nella maggior parte dei casi, esclusivamente dialettofoni. Oltre ad occuparsi del repertorio linguistico

\footnotetext{
* Universidade Federal de Santa Catarina, Florianópolis (Brasil) - carolinatorq@ gmail.com
}

DOI: http://dx.doi.org/10.11606/issn.2238-8281.v0i35p15-28 
degli immigrati, l'articolo riflette sulla repressione linguistica da loro subita all'epoca dell'Estado Novo e delle conseguenze di questa repressione sulle nuove generazioni di discendenti. L'obiettivo dell' articolo è problematizzare la relazione che si stabilisce tra la repressione linguistica e i pregiudizi ancora esistenti in relazione al/ai dialetto/i, discutendo la questione del ruolo dell'insegnamento dell'italiano in queste comunità.

PAROLE CHIAVE: lingue d'immigrazione; dialetto; italiano; talian; insegnamento.

ABSTRACT: This paper focuses on the teaching of Italian language in public schools in some cities of the state of Santa Catarina in Brazil by framing it into the context of Brazilian linguistic diversity. In the last decades, cities founded by Italian immigrants that arrived in Brazil during the XIX century promulgated laws that assured the inclusion of the Italian language in the curriculum of their public school system, even though the majority of the immigrants spoke Italian dialects. The article, then, besides dealing with the linguistic repertoire of the immigrants, shall also try to analyze the linguistic oppression that those immigrants were subjected to during the Estado Novo period of Brazilian politics, seeking to access the consequences of that oppression for the new generations. The chief aim of the paper is, therefore, to problematize the relationship between linguistic oppression and prejudices still in place regarding the use of Italian dialects, trying to put into question the validity of the teaching of standardized Italian in communities formed mainly by dialectophones.

KEYWORDS: immigration languages; dialects; Italian; Talian; language teaching. 


\section{Introdução}

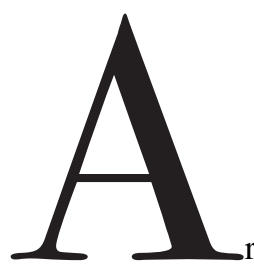

ealidade plurilíngue do Brasil constitui um patrimônio cultural ainda ignorado pela maior parte da população brasileira: além das variedades do próprio português brasileiro, estima-se que aqui sejam faladas mais de 250 línguas, entre línguas indígenas, línguas afro-brasileiras, línguas de imigração, línguas de sinais e línguas crioulas. Trata-se de uma ignorância historicamente produzida e politicamente alimentada, afinal, todo (des) conhecimento é político. De fato, como ressalta Oliveira,

não é por casualidade que se conhecem algumas coisas e se desconhecem outras: conhecimento e desconhecimento são produzidos ativamente, a partir de óticas ideológicas determinadas, construídas historicamente. No nosso caso, produziu-se o "conhecimento" de que no Brasil se fala o português, e o "desconhecimento" de que muitas outras línguas foram e são igualmente faladas. $\mathrm{O}$ fato de que as pessoas aceitem, sem discutir, 
como se fosse um "fato natural", que o "português é a língua do Brasil" foi e é fundamental para obter consenso das maiorias para as políticas de repressão às outras línguas, hoje minoritárias (2000, p. 83).

Certamente no passado era ainda maior o número de línguas faladas em território brasileiro - o que nos alerta para os riscos de uma perda cultural inestimável, caso outras línguas também sejam extintas. Diante de um patrimônio linguístico ainda pouco (re)conhecido, documentado e valorizado, é delicado e perigoso rotular uma língua como "materna" ou como "estrangeira" para diferentes grupos formadores da sociedade brasileira; mais do que isso, tentar homogeneizar a nossa diversidade linguística significa perpetuar a histórica exclusão de grupos sociais, dentre os quais as minorias étnicas. É por essas razões que, ao tratar de (ensino de) língua(s) no Brasil, convém tratar de um contexto sócio-histórico situado.

O contexto que interessa a este trabalho é o das comunidades de Santa Catarina, fundadas a partir da imigração italiana do final do século XIX e marcadas, desde o seu surgimento, pela diversidade linguística. Iniciaremos questionando que língua(s) falavam os imigrantes italianos: com base na história linguística da Itália, procuraremos dissipar a persistente confusão entre (variedade de) italiano e dialeto(s), e resgatar o repertório linguístico dos imigrantes que se estabeleceram em Santa Catarina. Em seguida, o artigo trata da diversidade linguística como estopim para a repressão cultural sofrida pelos imigrantes durante o Estado Novo, e aborda as consequências dessa repressão para as novas gerações de descendentes. O objetivo do artigo é problematizar a relação que se estabelece entre a repressão linguística e os preconceitos ainda existentes quanto ao(s) dialeto(s), questionando o lugar do ensino do italiano nessas comunidades.

Nesse percurso, teremos a possibilidade de notar que "o presente está repleto de passado e vice-versa" (BOTELHO; SCHWARCZ, 2011, p.15); de fato, ao abordar, ao longo do artigo, questões de (ensino de) língua, de identidade e de memória, veremos emergir os conflitos linguísticos, culturais e sociais do passado e do presente - ou melhor, os conflitos de um presente "repleto de passado e vice-versa". Para abarcar os pontos de tensão inerentes ao tema, o artigo se apoia na história linguística italiana e na Linguística Aplicada - aqui compreendida como área inter/transdisciplinar, que não exclui perspectivas complementares oferecidas por outras áreas das ciências humanas. Ao atravessar terrenos fronteiriços, que partem do contexto dos imigrantes para o contexto do ensino da língua, este trabalho procura fazer vir à tona as vozes dos sujeitos sociais, a partir do testemunho de professoras de italiano da rede pública de ensino de Santa Catarina. 


\section{O passado repleto de presente}

Foram variadas, no tempo e no espaço, as formas que tomou a imigração italiana no Brasil - tanto quanto foram variadas as formas que tomou a escravidão e a transição da escravidão ao trabalho livre -, contudo, pode-se afirmar que a imigração italiana do final do século XIX atendeu a interesses socioeconômicos do Brasil e da Itália. Por um lado, pressionado a abolir a escravidão, o Brasil precisava ocupar territórios e inovar as técnicas de agricultura; além desses fatores, é inegável que o racismo e a perversa política de branqueamento da população também pesaram no incentivo ao grande afluxo de imigrantes europeus. Por outro lado, a Itália, recém-unificada, enfrentava uma grave crise econômica e procurava se firmar como país industrializado, deixando às margens parte significativa de sua população, sem trabalho e sem perspectivas. Assim, a vinda dos imigrantes italianos no período imediatamente seguinte à abolição da escravidão respondeu a demandas e a interesses tanto do Brasil quanto da Itália.

No contexto situado que interessa a este artigo, o das áreas coloniais de Santa Catarina, grande parte dos imigrantes se instalou em pequenas propriedades rurais e, em muitos casos, junto de grupos provenientes da mesma região da Itália (em colônias nas quais predominavam os vênetos, ou colônias em que predominavam os trentinos, por exemplo). A estrutura minifundiária das colônias e a organização do povoamento, a partir de grupos de conterrâneos, foram fatores que, inicialmente, contribuíram para a preservação da(s) língua(s) dos imigrantes.

Que língua(s) falavam os imigrantes italianos parece não ser uma questão clara, já que no Brasil, de maneira geral, mesmo nas regiões de colonização italiana, há uma grande confusão entre italiano e dialeto, entre dialeto e talian, entre variedade de italiano e (variedade de) dialeto, entre "italiano de cá" e "italiano de lá", entre "o nosso" italiano e o italiano "gramatical", enfim, entre um suposto italiano "errado" e um suposto italiano "correto". Não é banal, portanto, questionar: que língua, afinal, falavam os imigrantes italianos quando vieram para Santa Catarina? E ainda: qual foi a herança linguística/cultural que deixaram a seus descendentes?

Para compreender o contexto linguístico no qual estavam inseridos os imigrantes, vale retomar brevemente alguns dados da história linguística da Itália que possam desfazer as confusões. Um primeiro ponto a ser esclarecido diz respeito justamente às concepções de "língua" e de "dialeto". Não há uma interpretação unívoca de "dialeto", contudo, sob a perspectiva da linguística, o termo geralmente é compreendido de duas maneiras: (1) como um sistema linguístico autônomo em relação à língua nacional; ou (2) como variedade da língua nacional. Convém, portanto, esclarecer que no caso específico da situação linguística italiana vale a primeira acepção de dialeto, ou seja, quando se fala de um dialeto da Itália, se fala de uma língua autônoma em relação à língua italiana.

O repertório linguístico da Itália atualmente inclui, de um lado, a língua italiana e suas variações (diatópica, diastrática, diamésicas etc.), de outro, os dialetos (piemontês, lombardo, vêneto, friulano, apenas para citar alguns exemplos) e suas variações (considerando o dialeto 
vêneto, por exemplo, temos o vêneto coloquial, o vêneto formal, o vêneto literário, e assim por diante). Em outras palavras, na história linguística italiana, e na complexidade de seu atual quadro plurilíngue, dialeto não se confunde com italiano, porque os dialetos da Itália não são variedades da língua italiana. Dialeto(s) e italiano são línguas diferentes que, como todas as línguas, variam em função do tempo, da origem geográfica de seus falantes, da classe social, do grau de escolarização, da idade, do contexto de comunicação etc.

O território italiano sempre foi marcado pela fragmentação linguística: das variedades regionais de latim vulgar foram surgindo os idiomas neolatinos, dentre os quais os inúmeros dialetos que continuam compondo o atual quadro linguístico da Itália. Os dialetos existentes ainda hoje na Itália eram um vulgar, como o próprio dialeto toscano, elevado posteriormente ao status de língua nacional. Vale lembrar que até o Renascimento não havia um modelo de língua no território italiano, isto é, não havia um vulgar hegemônico: os diversos dialetos tinham autonomia e muitos deles já contavam com uma certa tradição escrita - em alguns casos, inclusive literária. É por essa razão que, até o Renascimento, não há propriamente o que se possa chamar de língua italiana.

É a partir do Renascimento, momento da codificação gramatical, que se institucionaliza a oposição entre italiano (compreendido como língua comum escrita) e dialeto (língua local falada), após um acalorado debate sobre a norma linguística, em que o prestígio da produção literária toscana do século XIV rende ao dialeto toscano a primazia sobre os demais dialetos. O fato de o modelo linguístico proposto ter se baseado no registro escrito de três autores toscanos (Dante, Petrarca e Boccaccio) do século XIV - isto é, o modelo de língua se espelhava na literatura de dois séculos antes - explica uma particularidade da história linguística italiana: a de o italiano ter se consolidado primeiramente como código comum escrito, tendo se estabelecido como língua comum falada apenas recentemente, em meados do século XX.

A adoção de um modelo de língua elitista, baseado apenas na literatura e desvinculado do uso efetivo, revela a razão de uma tardia italofonia: estima-se que em 1861, período da unificação da Itália, mais de $90 \%$ da população era exclusivamente dialetófona, ou seja, era capaz de se comunicar apenas em dialeto; ainda em 1951, cerca de $60 \%$ da população italiana era exclusivamente dialetófona, o que significa que somente a partir da segunda metade do século XX o italiano se tornou a língua falada pela maioria dos italianos. Depreende-se desses dados históricos que no período da imigração italiana em Santa Catarina, no final do século XIX, o que hoje chamamos de italiano ainda era uma língua restrita a uma pequena elite, a um pequeno grupo de letrados. Em outras palavras, para os imigrantes italianos que se estabeleceram em Santa Catarina, assim como para a maioria da população italiana da época, a língua materna era um dialeto da Itália, e não o italiano.

A importância de se retomar esses dados históricos sobre o contexto linguístico dos imigrantes diz respeito ao que constitui a identidade e a memória das comunidades catarinenses fundadas pela imigração italiana. O dialeto era, afinal, a primeira língua de aquisição dos 
imigrantes, e também das primeiras gerações de seus descendentes - antes que se tornassem alvo de uma forte repressão cultural, como veremos mais adiante. O dialeto era a língua de seus iguais, era a língua que permitia a socialização nos espaços públicos e privados.

De maneira geral, a opinião comum tende a associar maior prestígio à língua, relegando ao dialeto o estigma de uma posição subalterna, de uma cultura supostamente arcaica, vinculada sobretudo ao uso oral - daí as frequentes polêmicas do tipo "o vêneto não é um dialeto, é uma língua”, na tentativa de emprestar maior prestígio a um ou a outro dialeto. Sob a perspectiva da linguística, contudo, não existe diferença estrutural entre língua e dialeto: ambos são línguas resultantes de uma longa história, têm gramática, vocabulário, variedades. Não há razão, portanto, para evitar falar de "dialeto" quando se fala da língua dos imigrantes italianos.

No caso específico de Santa Catarina, a maioria dos imigrantes italianos era proveniente do Nordeste da Itália e falava o vêneto, mas havia também um número expressivo de imigrantes que falava o trentino, o friulano, o bergamasco - além de outros dialetos, em menor proporção. É importante esclarecer, ainda, que mesmo dentre os imigrantes provenientes de uma mesma região, como no caso dos vênetos, havia grupos provenientes de diferentes províncias vênetas (por exemplo, Vicenza, Belluno, Treviso), o que significa que falavam dialetos locais diferentes (vicentino, bellunese, trevigiano).

Compreendemos, assim, que se os imigrantes eram dialetófonos, não eram necessariamente falantes de um mesmo dialeto. Uma vez estabelecidos nas colônias de Santa Catarina, tiveram contato com imigrantes falantes de outros dialetos e, evidentemente, também com brasileiros. No sul de Santa Catarina, por exemplo, podemos citar o caso de cidades vizinhas como Nova Veneza, Treviso, Siderópolis e Urussanga, nas quais falantes de vêneto, de bergamasco, de friulano conviviam entre si. Do encontro e do convívio entre falantes de línguas/dialetos diferentes foi surgindo o talian, koiné que permitia a comunicação entre falantes de dialetos tão diferentes quanto o bergamasco e o vicentino, por exemplo. No final de 2014, o talian foi reconhecido como língua de imigração e incluído no Inventário Nacional da Diversidade Linguística, recebendo o título de Referência Cultural Brasileira; em Santa Catarina, o talian já havia sido declarado "patrimônio histórico e cultural do Estado" em 2009.

Antes desse reconhecimento institucional da língua, porém, os imigrantes sofreram uma violenta repressão institucional, que teve como estopim justamente a diversidade linguística. Durante o Estado Novo, o nacionalismo - e sua suposta tarefa de construir uma brasilidade - deixou um rastro de violência contra os imigrantes e seus descendentes, considerados "alienígenas" a serem assimilados, "abrasileirados", integrados à sociedade brasileira:

Entre 1937 e 1945 uma parcela significativa da população brasileira sofreu interferências na vida cotidiana produzidas por uma "campanha de nacionalização" que visava ao caldeamento de todos os alienígenas em nome da unidade nacional. A categoria "alienígena" - preponderante no jargão oficial - englobava imigrantes e descendentes de imigrantes classificados 
como "não-assimilados", portadores de culturas incompatíveis com os princípios da brasilidade. A campanha foi concebida como "guerra" para erradicação de ideias alienígenas, com o objetivo de impor o "espírito nacional" aos patrícios que formavam "quistos étnicos" erroneamente tolerados pelo liberalismo da República Velha (SEYFERTH, 1997).

O uso de termos como "alienígenas" e "quistos étnicos" revela como a política nacionalista concebia os diferentes grupos de imigrantes, transformados pela linguagem "em elementos patológicos, supondo a necessidade de remoção" (SEYFERTH, 1997). Como patologia a ser extirpada, como desvio a ser corrigido, como ameaça à unicidade da identidade nacional, os imigrantes foram alvo de políticas restritivas que procuravam apagar as diferenças que os constituíam - e um dos traços que constituíam os imigrantes era a diversidade linguística. Foi justamente o uso de outras línguas nas colônias de Santa Catarina - de línguas que não correspondiam ao projeto ideológico da política estadual e nacional - o estopim para uma repressão desculturadora, que tentou aniquilar a identidade e a memória dos imigrantes. Dentre as medidas restritivas adotadas pelo regime de Vargas, estava a limitação no número de entrada de novos imigrantes, a "nacionalização do ensino" - com a obrigatoriedade do ensino da língua portuguesa e com o fechamento de escolas de colônias -, e o uso do exército como forma de coação.

Em diversos textos da época, a língua é concebida como um dos pilares simbólicos da nação e da almejada homogeneidade nacional, ou seja, como traço constitutivo de pertencimento a um grupo social maior; assim, por conceber a língua como critério fundamental da identidade nacional, a política nacionalista procurava justificar inclusive o fechamento das escolas étnicas, ainda que isso pudesse acarretar graves consequências nas áreas de colonização. Segundo um dos textos da época, "antes criarmos ignorantes, que criarmos traidores!" (cf. SEYFERTH, 1997, p. 95). Falar outra língua, portanto, tinha se tornado sinônimo de traição. Nesse sentido, o Estado Novo

marca o ponto alto da repressão às línguas alóctones, através do processo que ficou conhecido como "nacionalização do ensino" e que pretendeu selar o destino das línguas de imigração no Brasil, especialmente o do alemão e do italiano na região colonial de Santa Catarina e do Rio Grande do Sul. Foi nesses dois estados, nos quais a estrutura minifundiária e a colonização homogênea de certas regiões garantiram condições adequadas para a fixação do alemão e do italiano, que a repressão linguística, através do conceito jurídico de "crime idiomático", inventado pelo Estado Novo, atingiu sua maior dimensão (OLIVEIRA, 2000, p.87).

A mesma massa de gente que no século XIX foi usada para servir aos interesses políticos e econômicos do Brasil e da Itália, no século XX foi perseguida por uma ideologia nacionalista e 
xenófoba. A língua foi o pretexto e, ao mesmo tempo, o instrumento para a humilhação e para a repressão. As formas de violência sofridas foram as mais diversas: proibição de uso de outras línguas; prisão por 24 horas; trabalhos forçados por longos períodos; obrigação de beber óleo de rícino (ou lubrificante) e defecar em público; invasão de domicílios; queima de livros, fotos e recordações pessoais; extorsão etc. A violência física e moral atravessou todas as gerações de colonos, dos idosos às crianças, e se instalou em todos os ambientes sociais: das escolas às gráficas de jornais, dos domicílios às inscrições dos túmulos nos cemitérios. Os policiais "rasgavam e queimavam tudo o que não fosse brasileiro" (MOSER, 2004), e muitas vezes os próprios colonos, para tutelar a si e aos seus, destruíam ou escondiam tudo o que representava o vínculo com a língua e com as suas origens, como testemunham os descendentes (MOSER, 2004):

A maioria tinha muito medo. Havia pessoas que queimaram muitos livros, talvez muitas lembranças, por exemplo, imagem de um santo que estava escrito embaixo em italiano, eram queimados e jogados fora. Eram muitas coisas, documentos foram jogados fora, queimados, escondidos. Eu me lembro daqueles jornais que eu tinha falado antes: meu pai pegou, botou num caixão, pregou e levou num capinzal, lá em cima, no meio do mato. (Depoimento de um homem nascido em 1923).

O meu pai tinha espingarda e livros italianos. Teve que levar tudo embaixo de uma pedra no morro do Arduino Dalpiaz. Se viessem os investigadores e pegassem, ia todos para a cadeia. Os livros apodreceram. (Depoimento de um homem nascido em 1907).

Ser coagido a destruir ou a enterrar não apenas os próprios pertences, mas tudo o que constitui a memória (afetiva, social, cultural), a identidade de si e de seu grupo social, é o símbolo de uma violência institucionalizada que devastou a dignidade de gerações de imigrantes. Destituídos do direito de falar a própria língua, obrigados a vivenciar o apagamento de sua cultura e de sua ancestralidade, os imigrantes foram desapropriados de si. A língua que antes era materna, da aceitação, do acolhimento, da memória e da identidade, agora era a língua que causava discriminação, exclusão, violência e humilhação.

\section{O presente repleto de passado}

Foi por meio de uma violência institucionalizada, portanto, que o português se tornou a língua das gerações seguintes dos imigrantes. Como vimos, essa imposição hegemônica teve um alto custo, pago na pele e na memória dos colonos; compreende-se, assim, porque é delicado rotular a priori uma língua como "materna" ou como "estrangeira" para um determinado sujeito ou para um grupo social, afinal, é preciso considerar que 
há diversas maneiras de ser/estar-entre-línguas: para uns e em certas circunstâncias, é a língua estrangeira que constitui o lugar do repouso, que permite esquecer as experiências negativas ou até traumáticas do período da aquisição (oral ou escrita) da língua (dita materna), experiências essas que permaneceram cravadas no inconsciente em forma de interditos e de medo de se exprimir. Para outros, um sentimento de mal-estar emerge frequentemente através de uma espécie de embaraço cultural provocado pela língua do outro em confronto com a língua dita materna, suposto lugar de afeição e de completude (ainda que ilusória) onde se produz o sentimento de segurança da identidade (CORACINI, 2007, p.131).

Essas diferentes maneiras de "ser/estar-entre-línguas" parecem permear especialmente (ou sobretudo) a trajetória dos sujeitos marcados pela imigração - vivida na pele ou por ela transmitida. A política nacionalista não possibilitou a integração dos colonos, ao contrário: a assimilação forçada significou a tentativa de apagá-los, arrancando-lhes o que tinham de mais humano, a linguagem, para reduzi-los a uma massa de ninguéns que precisou se moldar, mais uma vez, aos interesses ideológicos do Estado. A repressão desumanizadora deixou suas consequências: ao mesmo tempo em que instalou medo e vergonha de falar a própria língua, foi naturalizada e silenciada por décadas. O silêncio dos oprimidos dilacerou a herança linguística, impedindo que as gerações seguintes se apropriassem da língua de seus ancestrais.

A dinâmica com que se deu a repressão contra os imigrantes, como explica Bueno, é própria do "regime da assimilação", em que "o Outro deve, para se integrar ao grupo detentor dos valores de referência, renegar os traços que o constituem para poder se tornar o Mesmo" (2013, p.39). Renegar os próprios traços constitutivos, renegar a própria língua, foi a herança mais perversa da investida nacionalista contra os imigrantes e seus descendentes, entretanto, não se tratou de um episódio isolado ou sem precedentes, afinal, a repressão sempre marcou a história linguística brasileira. De fato, no Brasil,

a política linguística do Estado sempre foi a de reduzir o número de línguas, num processo de glotocídio (assassinato de línguas), através de deslocamento linguístico, isto é, de sua substituição pela língua portuguesa. A história linguística do Brasil poderia ser contada pela sequência de políticas linguísticas homogeneizadoras e repressivas e pelos resultados que alcançaram (OLIVEIRA, 2000, p.84).

As políticas linguísticas homogeneizadoras, no que diz respeito às comunidades de colonização italiana, parecem não ter acabado com a repressão ocorrida durante o Estado Novo. Conforme já pudemos discutir, os imigrantes eram dialetófonos (quer dizer, para eles e para seus descendentes, falar o dialeto assegurava o pertencimento a um grupo social); a língua italiana não constitui a história, a memória e a identidade desses grupos sociais, contudo, 
atualmente é o italiano a ser ensinado nas escolas de diversos municípios catarinenses de colonização italiana. Cerca de um século após a chegada dos imigrantes em Santa Catarina, alguns desses municípios promulgaram leis que incluem a língua italiana no currículo das escolas da rede municipal - este é o caso de Urussanga, Nova Veneza, Siderópolis, Arroio Trinta e Celso Ramos, apenas para citar alguns exemplos. Há também municípios em que o italiano é oferecido como matéria extracurricular e/ou no contra-turno.

É importante esclarecer que, mesmo dentre esses municípios em que o italiano está presente na rede pública de ensino, não há uma situação homogênea que permita generalizações, isto é, há municípios em que o italiano é ensinado do $1^{\circ}$ ao $9^{\circ}$ ano do Ensino Fundamental (é o caso de Nova Veneza e Salto Veloso, por exemplo), há municípios em que é ensinado do $1^{\circ}$ ao $5^{\circ}$ ano do Ensino Fundamental (como Urussanga) e há, ainda, municípios em que o italiano é matéria curricular, mas não está presente em todas as escolas do município (é o caso de Concórdia, em que recentemente o italiano foi substituído pelo espanhol numa de suas escolas, por opção da "comunidade escolar"). É também importante ressaltar que raras são as escolas estaduais em que a língua italiana foi incluída no currículo, a despeito do interesse das comunidades: num mesmo município, portanto, há crianças que estudam italiano do $1^{\circ}$ ao $9^{\circ}$ ano do Ensino Fundamental (nas escolas municipais), mas não têm continuidade no Ensino Médio (nas escolas estaduais), além do caso de crianças que não têm contato com o italiano em nenhum momento, por seguirem todo o seu percurso escolar apenas nas escolas estaduais.

Além dessas diferenças que não permitem generalizações no que diz respeito ao ensino do italiano nas escolas públicas de Santa Catarina, há diferenças relevantes entre escolas de um mesmo município. As professoras percebem atitudes diferentes das crianças e dos jovens em relação ao ensino do italiano, geralmente vinculadas à localidade da escola: nas escolas mais próximas do centro urbano as crianças parecem ter pouco ou nenhum contato com o dialeto em casa, e mais resistência ao aprendizado do italiano, enquanto nas escolas do campo (ou mais próximas de áreas rurais) tende a ser mais expressivo o número de crianças que ainda ouvem o dialeto em família e que demonstram interesse em aprender italiano na escola.

O fator rural/urbano, portanto, parece ser determinante tanto na sobrevivência e na preservação dos dialetos quanto na maneira como as crianças e os jovens encaram o ensino do italiano na escola. Aliás, mais do que apenas uma questão de localidade, o fator rural/urbano traz à tona fatores sociais relevantes para a educação: mais de um século depois da fundação das colônias, a atual estrutura social dos municípios revela que no centro urbano as crianças e os jovens tendem a adotar e/ou desejar um estilo de vida mais próximo ao das capitais/metrópoles brasileiras, distanciando-se das tradições culturais locais, enquanto nas áreas rurais o convívio com a família e com os valores por ela transmitidos parecem ainda ser preponderantes. Em outras palavras, no campo a família tende a ser mais presente e mais participativa na educação das crianças, e as professoras relatam os reflexos dessa presença tanto no comportamento das crianças em sala de aula quanto no convívio mais harmônico com a cultura do nono e da nona. 
Nos casos em que as crianças têm a possibilidade de ouvir o dialeto em casa, é clara a percepção de que o italiano da sala de aula não corresponde à língua falada pelo nono e pela nona. As professoras relatam tanto exemplos em que são repreendidas pelas crianças ("não é assim que a nona fala, maestra!") quanto exemplos em que as crianças repreendem os avós, por considerarem "correto" o italiano ensinado na escola. A idade, aliás, também é identificada pelas professoras como fator importante no modo como os alunos reagem às aulas de italiano: em geral, as crianças se mostram mais receptivas e interessadas, além de curiosas sobre o contexto da imigração, enquanto os adolescentes tendem a apresentar mais resistência ao aprendizado do italiano, inclusive através de questionamentos sobre a presença da língua no currículo, supostamente "desperdiçando o tempo que poderia ser dedicado às aulas de inglês ou de espanhol". No testemunho de uma professora, vem à tona o presente repleto de passado: "os adolescentes acham brega falar italiano. Eles dizem que é coisa de colono, é coisa de gente da roça".

O estigma social, o desprestígio e a vergonha são os resultados da política homogeneizadora, que também se traduz na perda iminente das línguas de imigração. Silenciada por gerações, a repressão institucional fez com que os próprios descendentes renegassem a herança linguística de seus ancestrais; agora, a cada nova geração de descendentes de imigrantes, são cada vez mais raros os falantes de dialeto. Ainda que nas últimas décadas as comunidades tenham começado a manifestar o desejo de resgatar os traços linguísticos e culturais que as constitui, na prática há um abismo entre a língua dos imigrantes e a língua que se ensina hoje na escola.

A repressão cultural arrasou com a herança linguística que cabia aos descendentes, e o que ficou parece ser um emaranhado nebuloso: no desejo de preservar a memória, afloram equívocos históricos, por não se compreender bem que língua e que cultura constituíam os imigrantes. É o que se vê nas festas comunitárias ou nas ocasiões solenes dessas comunidades, quando é possível se deparar com o canto e com a dança de músicas italianas que nada têm a ver com a cultura dos imigrantes: não raro, por exemplo, a célebre canção napolitana Funiculì funiculà, que não tem nenhum vínculo com a cultura (nem com a língua) do Nordeste da Itália, é cantada como se representasse a valorização da cultura dos imigrantes, o resgate de um patrimônio histórico.

No que diz respeito especificamente à língua, na já citada confusão entre variedade de italiano e dialeto, o "italiano de cá" geralmente é associado à língua estigmatizada, a uma cultura desprestigiada, considerada fundamentalmente agrária e antiquada; o dialeto é associado ao "colono" e à vida rural, como forma precária, "errada" de se comunicar. Por outro lado, o "italiano de lá" (da Itália de hoje) é associado à cultura urbana, contemporânea, é associado ao consumo de bens materiais e sociais e, portanto, ao prestígio; o "italiano de lá", enfim, é associado à "gramática", compreendida como forma "correta" de se comunicar, como forma que dá status ao falante. Nesse sentido, Cambrussi (2007) ressalta como as políticas de promoção linguística, ao privilegiarem e reforçarem as línguas de dominação, não chegam de fato a promover as línguas de imigração. 
O questionamento que cabe fazer aqui diz respeito, justamente, ao lugar do ensino do italiano nessas comunidades catarinenses. As políticas públicas de promoção linguística, através da sua inclusão do italiano no currículo das escolas, podem trazer benefício às línguas de imigração (aos dialetos, ao talian)? Se o objetivo das leis municipais era o de resgatar a herança cultural da comunidade, por que não se privilegiou o ensino do dialeto local ou do talian? E diante das leis já promulgadas, como evitar que o ensino do italiano reforce o estigma cultural e o apagamento dos dialetos? Esses são apenas alguns dos questionamentos que, diante da histórica repressão linguística vivenciada pelos imigrantes, não podem ser desconsiderados no planejamento de políticas públicas de promoção linguística nessas comunidades.

Conforme mencionamos no início deste artigo, "conhecimento e desconhecimento são produzidos ativamente, a partir de óticas ideológicas determinadas, construídas historicamente" (OLIVEIRA, 2000, p.83). O que pudemos observar, ao longo deste trabalho, é que o desconhecimento sobre a língua que falavam os imigrantes, e sobre a cultura que os constituía, foi ativamente produzido por uma repressão institucional que ainda deixa rastros em Santa Catarina. O resultado desse desconhecimento historicamente construído é a perda iminente da cultura dialetal e de um inestimável patrimônio imaterial, que inclui a identidade e a memória de grupos formadores da sociedade brasileira. É também resultado desse desconhecimento historicamente produzido o abismo que se instituiu entre a língua dos imigrantes e a língua que se ensina hoje nas escolas.

Trata-se de um abismo que, por falta de políticas públicas de promoção linguística mais adequadas às realidades locais, ainda se traduz em conflitos culturais e preconceitos linguísticos, dentro e fora da sala de aula. Os problemas colocados neste artigo, mais do que respostas simplistas ou generalizantes, pedem uma reflexão sobre o conhecimento que se deseja produzir ativamente para as novas gerações de descendentes. Evidentemente, os direitos linguísticos desses municípios de Santa Catarina construídos pelos imigrantes são permeados também pelo (direito ao) resgate de sua memória, de sua identidade e de sua autoestima, e esse é um percurso que só pode ser realizado se atravessar, de alguma maneira, a língua dos imigrantes e a cultura dialetal. Se a língua incluída nas escolas públicas foi o italiano, cabe, então, ao ensino do italiano evitar a continuidade do processo de apagamento da diversidade linguística que constitui a identidade e a memória dessas comunidades.

\section{Agradecimentos}

Agradeço às professoras de italiano da rede pública de ensino em Santa Catarina, especialmente às professoras de Nova Veneza, Siderópolis e Urussanga, pela confiança e pela generosidade em partilhar suas experiências e seus saberes, contribuindo para que este trabalho pudesse ser desenvolvido. Agradeço também a Eliane Albiero, da ALCIES (Associação de 
Língua e Cultura Italiana do Espírito Santo), por ter me levado a conhecer a situação do ensino do italiano nas escolas públicas.

\section{Referèncias}

BOTELHO, A.; SCHWARCZ, L. M. (orgs.). Agenda brasileira: temas de uma sociedade em mudança. São Paulo, Companhia das Letras, 2011.

BUENO, A. M. Língua, imigração e identidade nacional: análise de um discurso a respeito da imigração no Brasil da Era Vargas. Estudos Semióticos, v. 9 (n. 2), 2013. Disponível em: <http://www. revistas.usp.br/esse/article/view/69531>. Acesso: 01 de junho de 2017.

CAMBRUSSI, M. O efeito das políticas de promoção linguística para as línguas de imigração: o caso do talian e do italiano. Revista Língua \& Literatura, v. 9 (n. 13), 2007. Disponível em:

$<$ http://revistas.fw.uri.br/index.php/revistalinguaeliteratura/article/view/68>. Acesso: 01 de junho de 2017.

CORACINI, M. J. A celebração do outro: arquivo, memória e identidade. Campinas, Mercado de Letras, 2007.

MARCATO, C. Dialetto, dialetti e italiano. Bologna, il Mulino, 2007.

MOSER, A. A violência do Estado Novo Brasileiro contra os colonos descendentes de imigrantes italianos em Santa Catarina durante a Segunda Guerra Mundial. Disponível em: <http://www.ipol.org. br/ler.php?cod=200>. Acesso: 02 de fevereiro de 2017.

OLIVEIRA, G. M. Brasileiro fala português: monolinguismo e preconceito linguístico. In Silva, F. L.; Moura, H. M. M (orgs.). O direito à fala. Florianópolis, Editora Insular, 2000, p. 83-92.

SEYFERTH, G. A assimilação dos imigrantes como questão nacional. Mana, 1997, v. 3 (n. 1). Disponível em:

$<$ http://www.scielo.br/scielo.php?script=sci_arttext\&pid=S0104-93131997000100004\&lng=pt\&nr $\mathrm{m}=\mathrm{iso} \& \operatorname{lng}=\mathrm{pt}>$. Acesso: 01 de junho de 2017.

TESI, R. Storia dell'italiano. La lingua moderna e contemporanea. Bologna, Zanichelli, 2005.

.Storiadell'italiano. Laformazione dellalinguacomune.Bologna,Zanichelli, 2007.

Recebido em 05/10/2017

Aprovado em 19/11/2017 